\title{
Determinants of nutrition improvement in a large-scale urban project: a follow-up study of children participating in the Senegal Community Nutrition Project
}

\author{
A Gartner*, B Maire, P Traissac, Y Kameli and F Delpeuch \\ Nutrition Unit, UR 106 (WHO Collaborating Centre for Nutrition), IRD (Institut de Recherche pour le Développement), \\ BP 64501, 911 Avenue Agropolis, F-34394 Montpellier Cedex 5, France
}

Submitted 1 August 2005: Accepted 18 January 2006

\begin{abstract}
Objective: To study individual determinants of differential benefit from the Senegal Community Nutrition Project (CNP) by monitoring improvement in children's weightfor-age index (WA) or underweight status (WA $<-2 Z$-scores) during participation. Design: A follow-up study using the CNP child monitoring data. Linear general models compared variations in WA according to 14 factors describing the beneficiaries and CNP services.

Setting: Poor neighbourhoods of Diourbel, a large city in Senegal, West Africa. Over a 6-month period, the CNP provided underweight or nutritionally at-risk 6-35-monthold children with monthly growth monitoring and promotion and weekly food supplementation, provided that mothers attended weekly nutrition education sessions.

Subjects: All the children who participated in the first two years of the project $(n=4084)$.

Results: Mean WA varied from -2.13 (standard deviation (SD) 0.82) to -1.58 (SD 0.81) Z-scores between recruitment and the end of the follow-up. The lower the child's initial WA, the greater was their increase in WA but the lower was the probability of recovery from underweight. Only 61\% of underweight children recovered. Six months of CNP services may not be sufficient for catch-up growth of severely underweight children. The number of food supplement rations received was not a direct indicator of the probability of recovery. After adjustment for services received and initial WA, probability of recovery was lower in girls, in younger children, in twins and when mothers belonged to a specific ethnic group.

Conclusions: Determinants of benefit from CNP differed from the risk factors for underweight. Identification of participants with a lower probability of recovery can help improve outcome. Moreover, an explanation for the lack of recovery could be that many underweight children are stunted but not necessarily wasted.
\end{abstract}

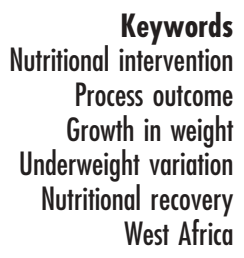

The effectiveness of a nutritional intervention in achieving weight gain or catch-up growth among undernourished children may depend on the specific context of its implementation, i.e. delivery and process outputs. However, among reasons why programmes should work in theory but do not work in practice could be that some causes of malnutrition which depend on the individual cannot be addressed by the intervention. Moreover, individual determinants of differential benefit from the intervention can differ from the targeting criteria or the risk factors of malnutrition. Consequently characterisation of the determinants of benefit, although rarely addressed, would be useful in order to help improve intervention outcomes.

The main focus of the present study was the individual determinants of differential benefit from the services delivered by the Community Nutrition Project (CNP) in Senegal, West Africa. The CNP is a large-scale intervention that was funded by the World Bank and was implemented over a 5-year period by a private agency AGETIP (Agence d'Exécution des Travaux d'Intérêt Public) ${ }^{1-3}$ in response to the increase in underweight prevalence from 14 to $17 \%$, from 1992/93 to 1996, among children aged 0-4.99 years in urban Senegal ${ }^{4-6}$. One of the objectives of the CNP nutrition components was to halt further deterioration in children's nutritional status in poor urban neighbourhoods ${ }^{1}$. As the priority outcome was to bring malnourished children back to normal growth, targeted participants in the CNP were 6-35-month-old children who were underweight (growth chart-based diagnosis of low weight-for-age index (WA)) or nutritionally at-risk (sibling of an underweight child or not having gained 
weight during the last three months). The CNP provided targeted children with monthly growth monitoring and promotion (GMP) and weekly food supplementation (FS) provided that their mothers attended weekly nutrition education (NE). These services were provided for a period of 6 months, during which monitoring performed by CNP workers allowed documentation of attendance at services and follow-up growth in weight. Moreover, detailed individual characteristics of participating children and their mothers were also available, thus allowing their effect on growth in weight to be assessed.

The aim of the present study was to assess the determinants of benefit in all children who participated in the first two years of the CNP in Diourbel, an inland city of about 77000 people in $1988^{7}$. Process results from this sample (assessed in another study) showed that only two-thirds of children were actually underweight at recruitment according to the cut-off point of WA $<-2$ $Z$-scores; attendance at GMP sessions (93\%) reached the expected level (90\%) whereas attendance at FS rations distribution (45\%) and NE sessions (62\%) was lower than expected (90\% for FS and 80\% for NE) ${ }^{8}$. A link between initial anthropometric status of the child and attendance at services was observed. Indeed, the higher proportion of initially underweight children in the groups of mothers who had better attendance rates at NE and FS suggests that the CNP workers were efficient in raising mothers' awareness of the nutritional status of their child and of the importance of attending the sessions in the case of malnutrition.

We explored whether the characteristics of the participating children and their mothers could influence the effect of the CNP services on the main process outcome (improvement in anthropometric status of participating children). For this purpose, we assessed the relationship of 14 individual factors (Table 1$)$ with WA variation $(\Delta \mathrm{WA})$ between recruitment and the end of the follow-up, and, in the subgroup of children who were underweight at recruitment, with recovery from underweight.

\section{Methodology}

\section{Subjects}

Subjects were all children who had participated in the first two years of the CNP in Keur Cheikh Ibra, the first district in Diourbel targeted by the CNP where $28 \%$ of $6-35-$ month-old children were underweight ${ }^{9}$. This follow-up study was based on data collected by CNP workers. For the purpose of the study, data from monitoring record cards of the participating children and their mothers were computerised. All children who underwent at least one body weight measurement (i.e. the one used for recruitment) were included, yielding a quasi-exhaustive sample $(n=4084)$. As attendance at GMP was very good (mean duration of $5.8 \pm 0.9$ months for the 6-month duration planned ${ }^{8}$ ), longitudinal growth data were

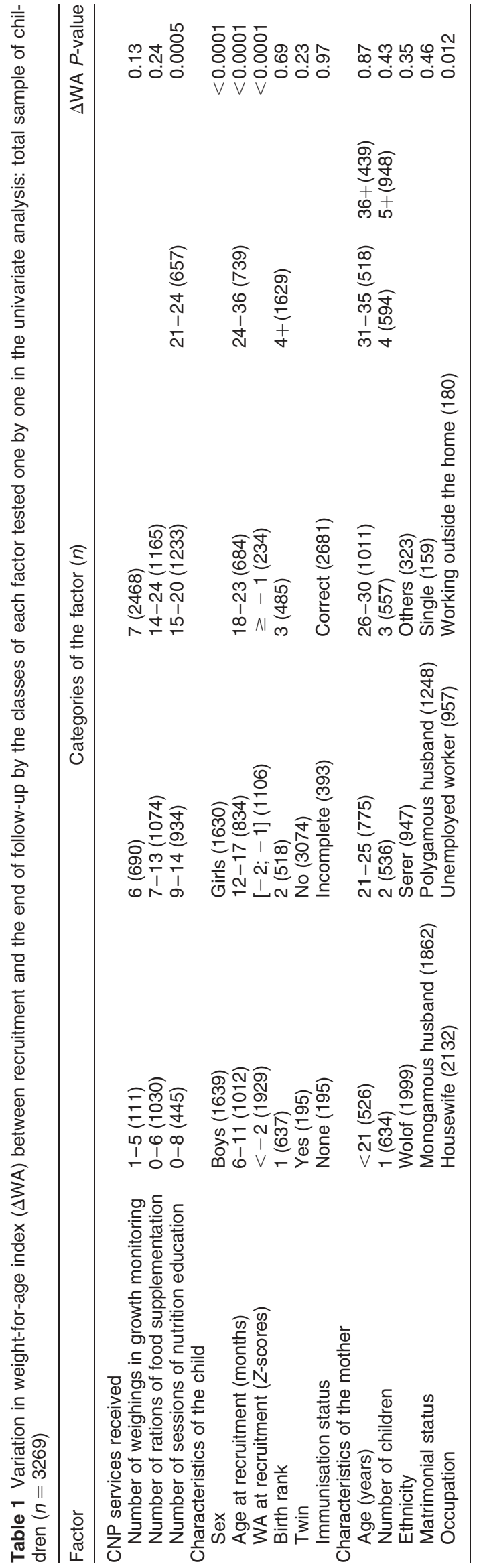


available for most of the children; only $5 \%$ of the sample attended GMP for less than 4.5 months, which was considered insufficient. Children who attended GMP for less than 4.5 months were thus excluded from the present study, as well as those for whom data were missing for any of the 14 explanatory variables. This resulted in a sample of 3269 children ('total' sample). Absence of bias was checked by comparison with the initial exhaustive sample. For analyses dealing specifically with children who were underweight at recruitment, the sample size was 1929.

\section{Antbropometry}

Children's body weight measurements had been taken by CNP teams to the nearest $100 \mathrm{~g}$ using a hanging baby scale (Salter). The child's age, calculated from date of birth and date of weighing, and body weight were used to calculate the WA index. WA was expressed in $Z$-scores (WA continuous variable) and underweight was defined as WA $<-2 Z$-scores of the World Health Organization (WHO)/National Center for Health Statistics (NCHS) reference median $^{10}$ (WA dichotomous variable).

\section{Individual factors}

CNP monitoring cards provided characteristics of the child (sex, birth date, birth rank, twin or not, and data from his/her immunisation card) and his/her mother (age, number of children, ethnicity, marital status, occupation). They also provided information on the CNP services received: attendance yes or no $(y / n)$ of the child at each of the monthly GMP sessions for the six weighings following initial weighing at recruitment, and, when yes, the body weight; attendance $(y / n)$ by the mother at each of the weekly NE sessions sessions, i.e. 24 sessions; whether $(\mathrm{y} / \mathrm{n})$ each of the weekly FS rations was actually given to the mother for the child, i.e. 24 rations.

The children were grouped into three categories according to their immunisation status. In the first, immunisation status was correct for his/her age with respect to the different minimal number of immunisations received before or after the age of 9 months (tuberculosis and diphtheria-tetanus-poliomyelitis expected to be received before 9 months, and measles and yellow fever expected from 9 months on). The other two categories were children with no or incomplete immunisation.

\section{Data management and statistical analysis}

Computerisation of data from monitoring cards was validated by double entry. Data entry and computation of the WA index were performed with Epi-Info $6.04 \mathrm{~d}^{11}$. Data management and statistical analyses were performed using the SAS system (SAS Institute Inc., Cary, NC, USA), release 8.2 .

The main purpose of all the analyses was to assess whether variation in WA between recruitment and end of follow-up (i.e. with 'time') differed according to the categories of each of the factors used as regressors in general linear models ${ }^{12}$.

For continuous WA in the 'total' sample, the 'time' dimension was included in the response variable $\Delta \mathrm{WA}$, which was calculated as WA at the end of follow-up minus WA at recruitment, regardless of the exact duration of GMP.

For dichotomous WA in the 'underweight at recruitment' sample, the 'time' dimension was also included in the response variable 'underweight recovery', which was defined according to whether or not the underweight children had recovered (WA $\geq-2 Z$-scores) at the end of follow-up. Suitable generalised linear models ${ }^{13}$ (modified Poisson regression ${ }^{14,15}$ ) were used. Differences in the proportion of recoveries between categories of a factor are displayed as prevalence ratios ${ }^{16}$ in comparison to a reference category.

Before retaining explanatory variables in the final models, we deemed it necessary to check whether individual characteristics were potential modifiers of the effect of the CNP services on variation in WA. This was done by testing, in separate models, the significance of interaction terms established between each of the three CNP services and each potential effect modifier among the child's or mother's characteristics.

In the final multivariate models, we kept all variables that were significant in the univariate analysis and only the interaction terms (and, of course, the two corresponding variables) that presented a significant link with the response variable. The presence of effect modifiers prevented interpretation of the main effect of the CNP variables and results are thus presented in a disaggregated analysis.

The sample of participating children resulting from the collection of individual cards in the CNP was exhaustive with reference to the population studied. However, despite the fact that the computed values for the parameters (means, prevalence and measures of association) were those of the population under study, we computed confidence intervals and/or $P$-values for the associations tested, mainly for the purpose of screening the explanatory variables. Confidence intervals (CI) are given at a 0.95 level. For all tests, the type 1 error risk was set at 0.05 .

\section{Etbical considerations}

Investigators involved in this study accessed information on CNP participants by entering data from individual forms stored by CNP workers with full agreement of CNP leaders. The name of the subject was not entered in the data file, ensuring confidentiality protection for individually identifiable information. Data were analysed independently from CNP leaders or workers, and the investigators had the responsibility for submitting this work for publication. 


\section{Results}

\section{Variation in antbropometric status between recruitment and the end of follow-up in all participating children}

Mean WA varied from -2.13 (standard deviation (SD) 0.82 ) $Z$-scores to -1.58 (SD 0.81 ) $Z$-scores, and mean $\Delta$ WA was $+0.55($ SD 0.65$) Z$-scores $(P<0.0001)$.

Five variables were linked $(P<0.05)$ to $\Delta \mathrm{WA}$ in the univariate analysis for each of the 14 variables (Table 1 ). $\Delta$ WA was higher in underweight children (mean (SD): +0.70 $(0.61),+0.42(0.61)$ and $-0.16(0.62)$ in the $<-2,[-2 ;-1]$ and $\geq-1 Z$-score WA categories, respectively), in boys $(+0.60(0.68)$ vs. $+0.49(0.62)$ in girls $)$, in older children $(+0.40(0.72),+0.63(0.64),+0.56(0.62)$ and $+0.63(0.55)$ in the $6-11,12-17,18-23$ and $24-36$ months age categories, respectively), in children whose mother was not working outside the home $(+0.55(0.65),+0.55(0.66)$ and $+0.40(0.62)$ in the housewife, unemployed worker and working outside the home categories of mother's occupation, respectively) and in children whose mother attended a higher number of NE sessions $(+0.56(0.59),+0.57$ $(0.67),+0.49(0.66)$ and $+0.61(0.64)$ in the $0-8,9-14,15-$ 20 and 21-24 sessions categories, respectively).

Factors that were linked to the response variable, plus mother's age, ethnicity and occupation that we chose to retain regardless of their link, were each tested as potential modifiers of the effect of each of the three CNP services. No factor modified the effect of GMP on $\Delta$ WA. The effect of NE on $\Delta$ WA was modified by the child's WA at inclusion $(P=0.013)$ and by the mother's occupation $(P=0.0002)$. The effect of NE on $\Delta$ WA was modified by the child's age $(P=0.047)$ and WA at inclusion $(P=0.025)$, and by the ethnicity $(P=0.015)$ and occupation $(P=0.0000)$ of the mother.

In the multivariate analysis, seven variables were retained in the model of $\Delta$ WA (Table 2). Among them, four were involved in three interaction terms (Table 2) and their results are detailed below for the disaggregated form. The lower the initial WA value, the higher the $\Delta$ WA and, moreover, a slight decrease in WA occurred when its value at recruitment was $\geq-1 Z$-score. Mean $\Delta$ WA was lower when the mother's ethnicity was Serer compared with other ethnic groups.

Mother's occupation was a modifier of the effect of FS on $\Delta$ WA: for 'housewife' mothers, the relationship is U-shaped ( $\Delta$ WA adjusted means of $+0.54,+0.51$ and +0.59 for the $0-6,7-13$ and 14-24 FS rations classes, respectively). Conversely for mothers 'working outside the home', the relationship is inverse U-shaped $(+0.50,+0.56$ and +0.27 , respectively). The overall lowest $\Delta$ WA adjusted mean $(+0.27)$ was observed in the highest 14-24 FS rations category and in mothers 'working outside the home'. In the group of 'unemployed' mothers, adjusted mean $\Delta$ WA did not differ with respect to FS rations number $(+0.56,+0.55$ and +0.56 , respectively).

Similarly, mother's occupation was also a modifier of the effect of NE on $\Delta$ WA: as above, for 'housewife' mothers there is a $U$-shaped relationship $(+0.73,+0.54,+0.46$ and +0.57 for the 0-8, 9-14, 15-20 and 21-24 NE sessions classes, respectively). Conversely, for the two other groups of mothers the relationship is again inverse U-shaped. In 'unemployed' mothers, adjusted mean $\Delta$ WA was $+0.60,+0.68,+0.51$ and +0.46 , and in mothers 'working outside the home' values were $+0.32,+0.53,+0.45$ and +0.43 for the $0-8,9-14,15-$ 20 and 21-24 NE sessions classes, respectively. The overall lowest $\Delta$ WA adjusted mean value $(+0.32)$ was observed for the $0-8$ NE sessions class when mothers worked outside the home. In each NE sessions class, the lowest $\Delta$ WA was always observed for mothers 'working outside the home'.

Child's age also modified the effect of NE on $\Delta$ WA. In each age class, the highest $\Delta$ WA adjusted mean was always observed in the $0-8 \mathrm{NE}$ sessions class $(+0.51,+0.75,+0.67$ and +0.76 for $6-11-, 12-17-, 18-23$ - and 24-35-month-old children, respectively). In the same way, it should be noted that, despite the interaction, the lowest $\Delta$ WA mean value

Table 2 Variation in weight-for-age index $(\triangle \mathrm{WA})$ (general linear model) in the multivariate analysis: total sample of children $(n=3269)$

\begin{tabular}{|c|c|c|c|c|}
\hline \multirow[b]{2}{*}{ Explanatory term } & \multirow[b]{2}{*}{ Interaction term } & \multirow[b]{2}{*}{$P$-value } & \multicolumn{2}{|c|}{ Adjusted $\Delta$ WA (Z-scores) } \\
\hline & & & Mean & Standard error \\
\hline Sex & & 0.87 & & \\
\hline Boys & & & +0.55 & 0.015 \\
\hline Girls & & & +0.54 & 0.015 \\
\hline WA at inclusion (Z-scores) & & $<0.0001$ & & \\
\hline$<-2$ & & & +0.71 & 0.014 \\
\hline$[-2 ;-1]$ & & & +0.42 & 0.019 \\
\hline$\geq-1$ & & & -0.18 & 0.040 \\
\hline Mother's ethnicity & & 0.0002 & & \\
\hline Wolof & & & +0.58 & 0.013 \\
\hline Serer & & & +0.48 & 0.020 \\
\hline Other & & & +0.54 & 0.033 \\
\hline Number of rations of supplement & $\times$ Mother's occupation & 0.048 & +0.27 to +0.59 (see text) & \\
\hline Number of education sessions & $\times$ Child's age at recruitment & 0.025 & +0.38 to +0.76 (see text) & \\
\hline Number of education sessions & $\times$ Mother's occupation & 0.0022 & +0.32 to +0.73 (see text) & \\
\hline
\end{tabular}


(respectively $+0.38,+0.56,+0.38$ and +0.60 for the four age classes) was always observed for the same class of 15-20 $\mathrm{NE}$ sessions. In addition, in each NE number category, the mean adjusted $\Delta$ WA was always lower for the youngest children: +0.51 vs. $+0.75,+0.67$ and +0.76 in the $0-8 \mathrm{NE}$ sessions class; +0.46 vs. $+0.61,+0.67$ and +0.62 in the 9-14 NE sessions class; +0.38 vs. $+0.56,+0.38$ and 0.60 in the $15-20 \mathrm{NE}$ sessions class; and +0.39 vs. $+0.65,+0.59$ and +0.60 in the $21-24$ NE sessions category compared with the three other age groups, respectively.

\section{Recovery from underweight among children who were underweight at recruitment}

The overall proportion of recovery from underweight was $60.7 \%$ (95\% CI 58.6-62.9\%). In the unadjusted analysis, eight variables were linked to recovery (Table 3). Recovery was higher in children whose mother received the lowest number of FS, in boys, in the oldest children, in the children with the highest WA values at inclusion, with a birth rank less than 4 , not a twin, without immunisation coverage, and whose mother's ethnicity was not Serer (Table 3). These eight variables plus mother's age and occupation were tested as potential modifiers of the effect of each of the three CNP services. The only two effect modifications observed were between FS and child's immunisation status $(P=0.039)$ and between NE and whether the child was or was not a twin $(P=0.037)$.

In the final model, six variables had significant independent effects (i.e. adjusted for each other) on recovery, and no effect modifications were retained (Table 3); five of these six variables were also linked to $\Delta$ WA in multivariate analysis. A higher probability of recovery was observed when the number of rations of FS was less than 7 , in boys compared with girls, in the older children, in the group of higher initial WA value, in children who were not a twin, and when the mother's ethnicity was not Serer (Table 3).

\section{Discussion}

Differential effects of the CNP as a function of individual characteristics were studied in the context of global improvement in the WA status of participating children. Concerning dependent variables, $\Delta \mathrm{WA}$ in $Z$-scores assessed the global shift in the distribution of WA, whereas recovery based on the WA $<-2 Z$-scores threshold concerned initially malnourished children.

\section{Effect of CNP services}

This study took place in a context where the attendance at GMP was very good. Thus, because of the quasi-uniform attendance at GMP among all children, it was not possible to find evidence of the effect of this CNP service on $\Delta$ WA or recovery proportions in our analyses. Without a specific evaluation of the impact of GMP, we cannot determine its contribution to nutrition improvement ${ }^{17}$. Due to the design of the CNP, the effect of the number of FS and NE should be linked as the CNP planned to provide FS to mothers only provided they attended NE. However, coverage of FS in children was lower than mother's attendance at NE, which could explain a different link between the number of FS or NE and the dependent variables studied here.

Despite the proven worth of FS to enhance the nutritional status of children in developing countries at critical ages when their nutritional needs are likely not to be provided for ${ }^{17-19}$, FS alone is not the best way to prevent undernutrition ${ }^{20}$. Although what is called NE may cover very different intervention contents, overall evidence-based efficiency and effectiveness of NE have been ascertained either as an additional service to FS or even as a main service ${ }^{19,21-26}$. Here $\Delta$ WA depended on both the FS and NE sessions services but in interaction with some individual characteristics. On the whole, in the most unfavourable case of variation in WA, i.e. when the mother was working outside the home, less improvement in $\Delta$ WA was observed when the mother received a large quantity of FS rations or attended few NE sessions. On the contrary, the highest change in mean WA was observed in each age category with $0-8$ NE sessions. Such paradoxical results are difficult to explain as information on the knowledge of the mothers of children recruited in CNP was not available.

The relationship between recovery from underweight and the number of FS appeared also to be paradoxical as the higher the number of FS, the lower the probability of recovery, even after adjustment in multivariate analysis. It is difficult to explain this result without information on household food security and the educational level of the mothers, and such data were not available from the CNP monitoring dataset. However, one conclusion is that the number of FS rations received is not a direct indicator of the probability of recovery from underweight.

\section{Effect of WA status at recruitment}

First, the largest $\Delta$ WA was observed in children who were underweight at recruitment, which is quite understandable as these children are likely to have a greater potential for catch-up growth than non-underweight children. This strongly suggests that including children who were not underweight or even children with an initial WA value $\geq-1 Z$-score in CNP was useless in terms of improvement in their WA status. As they are not the most resourceconsuming activities, GMP or NE could be still provided to all participants without major supplementary costs; it should however be noted that mothers of children who were not underweight were less diligent in attending NE or FS services ${ }^{8}$. By contrast, an expensive and not sustainable service such as FS should be targeted more specifically to malnourished children.

Second, considering underweight children, the probability of recovery was dramatically reduced when the 
Table 3 Recovery from underweight between inclusion and the end of follow-up in the classes of each factor (univariate analysis), and in the multivariate analysis (Poisson regression model): sample of children underweight at recruitment $(n=1929)$

\begin{tabular}{|c|c|c|c|c|c|c|c|c|c|}
\hline \multirow[b]{3}{*}{ Factor } & \multirow[b]{3}{*}{$n$} & \multicolumn{4}{|c|}{ Univariate analysis } & \multirow[b]{3}{*}{$P$-value } & \multicolumn{3}{|c|}{ Poisson regression model } \\
\hline & & \multicolumn{4}{|c|}{ Recovery* from underweight } & & \multicolumn{3}{|c|}{ PR } \\
\hline & & Rate (\%) & PR & $95 \% \mathrm{Cl}$ & $P$-value & & $\begin{array}{l}\text { Adjusted } \\
\text { rate of recovery }\end{array}$ & Adjusted PR & $95 \% \mathrm{Cl}$ \\
\hline \multicolumn{10}{|l|}{ CNP services received } \\
\hline GMP (number of weighings of the child) & & & & & 0.26 & & & & \\
\hline $1-5$ & 52 & 71.2 & 1.18 & $0.98-1.41$ & & & & & \\
\hline 6 & 435 & 60.7 & 1.01 & $0.92-1.10$ & & & & & \\
\hline 7 & 1442 & 60.3 & 1 & & & & & & \\
\hline FS (number of rations) & & & & & 0.035 & 0.0014 & & & \\
\hline $0-6$ & 543 & 64.5 & 1.12 & $1.03-1.23$ & & & 58.4 & 1.16 & $1.07-1.25$ \\
\hline $7-13$ & 649 & 61.3 & 1.07 & $0.98-1.17$ & & & 53.2 & 1.05 & $0.97-1.14$ \\
\hline $14-24$ & 737 & 57.4 & 1 & & & & 50.5 & 1 & \\
\hline NE (number of sessions) & & & & & 0.050 & & & & \\
\hline $0-8$ & 188 & 66.5 & 1.14 & $1.00-1.29$ & & & & & \\
\hline $9-14$ & 545 & 63.9 & 1.09 & $0.99-1.21$ & & & & & \\
\hline $15-20$ & 738 & 58.3 & 1.00 & $0.90-1.10$ & & & & & \\
\hline $21-24$ & 458 & 58.5 & 1 & & & & & & \\
\hline \multicolumn{10}{|l|}{ Characteristics of the child } \\
\hline Sex & & & & & 0.022 & 0.0015 & & & \\
\hline Boys & 1241 & 62.6 & 1.09 & $1.01-1.18$ & & & 55.6 & 1.11 & $1.04-1.19$ \\
\hline Girls & 688 & 57.3 & 1 & & & & 49.9 & 1 & \\
\hline Age at recruitment (months) & & & & & $<0.0001$ & $<0.0001$ & & & \\
\hline $6-11$ & 535 & 56.3 & 1 & & & & 47.7 & 1 & \\
\hline $12-17$ & 540 & 58.5 & 1.04 & $0.93-1.15$ & & & 54.7 & 1.15 & $1.04-1.26$ \\
\hline $18-23$ & 414 & 59.2 & 1.05 & $0.94-1.17$ & & & 51.8 & 1.09 & $0.99-1.20$ \\
\hline $24-36$ & 440 & 70.2 & 1.25 & $1.13-1.37$ & & & 61.9 & 1.30 & $1.19-1.42$ \\
\hline WA at recruitment (Z-scores) & & & & & $<0.0001$ & $<0.0001$ & & & \\
\hline$<-3$ & 359 & 18.1 & 1 & & & & 18.2 & 1 & \\
\hline$[-3 ;-2.5]$ & 513 & 54.0 & 2.98 & $2.36-3.77$ & & & 53.5 & 2.94 & $2.33-3.70$ \\
\hline$[-2.5 ;-2]$ & 1057 & 78.4 & 4.33 & $3.47-5.41$ & & & 77.2 & 4.24 & $3.40-5.29$ \\
\hline Birth rank & & & & & 0.0019 & 0.23 & & & \\
\hline 1 & 361 & 61.2 & 1.07 & $0.97-1.18$ & & & 52.6 & 1.00 & $0.92-1.09$ \\
\hline 2 & 301 & 67.4 & 1.18 & $1.07-1.30$ & & & 55.8 & 1.07 & $0.98-0.16$ \\
\hline 3 & 255 & 66.3 & 1.16 & $1.05-1.29$ & & & 56.8 & 1.09 & $0.99-0.19$ \\
\hline 4 or more & 1012 & 57.1 & 1 & & & & 52.4 & 1 & \\
\hline Twin & & & & & 0.020 & 0.036 & & & \\
\hline Yes & 116 & 50.0 & 1 & & & & 46.6 & 1 & \\
\hline No & 1813 & 61.4 & 1.23 & $1.02-1.48$ & & & 54.0 & 1.16 & $1.00-1.34$ \\
\hline Immunisation status & & & & & 0.037 & 0.29 & & & \\
\hline None & 107 & 70.1 & 1.25 & $1.06-1.48$ & & & 55.0 & 1.10 & $0.96-1.26$ \\
\hline Incomplete & 252 & 56.0 & 1 & & & & 49.9 & 1 & \\
\hline Correct & 1570 & 60.8 & 1.09 & $0.97-1.22$ & & & 54.0 & 1.08 & $0.97-1.20$ \\
\hline \multicolumn{10}{|l|}{ Characteristics of the mother } \\
\hline Age (years) & & & & & 0.37 & & & & \\
\hline$<21$ & 325 & 61.9 & 1.09 & $0.95-1.25$ & & & & & \\
\hline $21-25$ & 430 & 64.0 & 1.13 & $0.99-1.28$ & & & & & \\
\hline $26-30$ & 605 & 59.3 & 1.05 & $0.92-1.18$ & & & & & \\
\hline $31-35$ & 303 & 61.1 & 1.08 & $0.94-1.23$ & & & & & \\
\hline 36 or more & 266 & 56.8 & 1 & & & & & & \\
\hline Number of children & & & & & 0.16 & & & & \\
\hline 1 & 369 & 60.4 & 1.04 & $0.93-1.16$ & & & & & \\
\hline 2 & 305 & 66.6 & 1.15 & $1.03-1.28$ & & & & & \\
\hline 3 & 322 & 61.5 & 1.06 & $0.95-1.18$ & & & & & \\
\hline 4 & 366 & 59.6 & 1.03 & $0.92-1.15$ & & & & & \\
\hline 5 or more & 567 & 58.0 & 1 & & & & & & \\
\hline Ethnicity & & & & & $<0.0001$ & 0.0060 & & & \\
\hline Wolof & 1090 & 65.5 & 1.26 & $1.16-1.38$ & & & 55.9 & 1.13 & $1.05-1.22$ \\
\hline Serer & 662 & 51.8 & 1 & & & & 49.6 & 1 & \\
\hline Other & 177 & 64.4 & 1.24 & $1.09-1.42$ & & & 54.4 & 1.10 & $0.97-1.24$ \\
\hline Matrimonial status & & & & & 0.51 & & & & \\
\hline Monogamous husband & 1104 & 60.5 & 1.00 & $0.93-1.08$ & & & & & \\
\hline Polygamous husband & 744 & 60.4 & 1 & & & & & & \\
\hline Single & 81 & 66.7 & 1.10 & $0.94-1.30$ & & & & & \\
\hline
\end{tabular}




\begin{tabular}{|c|c|c|c|c|c|c|c|c|c|}
\hline \multirow[b]{3}{*}{ Factor } & \multirow[b]{3}{*}{$n$} & \multicolumn{4}{|c|}{ Univariate analysis } & \multicolumn{4}{|c|}{ Poisson regression model } \\
\hline & & \multicolumn{4}{|c|}{ Recovery* from underweight } & \multirow[b]{2}{*}{$P$-value } & \multicolumn{3}{|c|}{ PR } \\
\hline & & Rate (\%) & PR & $95 \% \mathrm{Cl}$ & $P$-value & & $\begin{array}{c}\text { Adjusted } \\
\text { rate of recovery }\end{array}$ & Adjusted PR & $95 \% \mathrm{Cl}$ \\
\hline Occupation & & & & & 0.35 & & & & \\
\hline Housewife & 1293 & 59.7 & 1.00 & $0.84-1.20$ & & & & & \\
\hline Unemployed worker & 552 & 63.2 & 1.06 & $0.88-1.28$ & & & & & \\
\hline Working outside the home & 84 & 59.5 & 1 & & & & & & \\
\hline Total & 1929 & 60.7 & & & & & & & \\
\hline
\end{tabular}

$\mathrm{PR}$ - prevalence ratio (value of recovery from underweight among the classes of each factor; class is beneficial if $\mathrm{PR}>1$ ); $\mathrm{Cl}-\mathrm{Confidence}$ interval; CNP - Community Nutrition Project; GMP - growth monitoring and promotion; FS - food supplementation; NE - nutrition education.

* Rate of children no longer underweight at the end of the follow-up.

child's initial WA was well below the threshold value of -2 $Z$-scores used to define underweight. Mainly severely underweight children (WA $<-3 Z$-scores), but also a large proportion of children with an initial WA value between -3 and $-2.5 Z$-scores, were still underweight at the end of their participation in the CNP. In a similar scale project in Bangladesh, Hossain et al. recently reported that severely underweight 12-23-month-old children enrolled in a supplementary feeding programme improved their WA $Z$-score although the improvements were not sufficient to result in high rates of recovery from malnutrition ${ }^{27}$. For the two years in Diourbel studied here, $45 \%$ of the underweight children who participated in the CNP had an initial WA value $<-2.5 Z$-scores. In these cases, six months of services seemed low given the outcome, and systematic screening should have been performed at the end of follow-up to ensure that if they were still underweight, these children could continue to participate in CNP.

When considering the quantitative variable WA in $Z$-scores, the CNP-targeted children with the lowest initial WA values can be assumed to be the most in need of a nutritional intervention and also those who will benefit the most from the CNP. Although this assumption appeared to be correct when the benefit was assessed using the continuous WA variable, this was not the case when a WA threshold was used as benefit criterion. In other words, determinants of benefit from CNP could differ from the targeting criteria.

However, beyond WA status at recruitment, variation in WA status also depended on other individual characteristics of the children and their mothers.

\section{Effect of individual characteristics}

Even after adjustment or as effect modifier, the child's age had an important and clear effect: the younger the child, the lower the $\Delta$ WA and the lower the rate of recovery. Again, Hossain et al. reported that severely underweight 6-12-month-old children enrolled in a supplementary feeding programme did not improve their WA $Z$-score whereas the 12-23-month-old children $\mathrm{did}^{27}$. In the present study, one possible explanation is that the food composition of the FS provided by the CNP, which is the same regardless of child's age between 6 and 36 months, was far more suited to the nutritional requirements of the older children than to those of the younger ones. From data of the WHO/NCHS anthropometric references ${ }^{10}$, we calculated approximate values of expected growth in body weight between the ages of 9 and 15, 15 and 21, 21 and 27, 27 and 33 months as means of what could be expected in the four age groups used in the analysis for a 6-month period of growth. It appeared that growth in body weight was close to that expected in the children with initial values of WA $\geq-1 Z$-score regardless of the age group. In children with initial WA value in the $[-2 ;-1]$ $Z$-scores range, growth in body weight was a little higher than expected (difference of about $+0.3 \mathrm{~kg}$ in boys and $+0.5 \mathrm{~kg}$ in girls) again regardless of the age group. Conversely, in children underweight at recruitment, growth in body weight was higher than expected, the difference being twice as high in the oldest children (approx. $+1.0 \mathrm{~kg}$ ) than in the youngest (approx. $+0.5 \mathrm{~kg}$ ). This confirms that, among CNP beneficiaries, catch-up growth was more favourable in older children, and the reason could be that the FS was inappropriate to address the nutritional requirements of younger underweight children. This problem is even more important in the cases where the CNP FS replace, rather than supplement, normal feeding of the child, as has frequently been reported and was directly evidenced in this programme ${ }^{28}$.

On the whole, the mother working outside the home appeared to be an unfavourable case for WA improvement compared with other occupation groups of the mothers. One explanation could be that, while working outside the home, the mothers were unable to see whether the FS was actually consumed by the child concerned. Indeed, it has been determined that the child actually eats only $25 \%$ of the FS brought home from the $\mathrm{CNP}^{28}$. Another explanation could be that, when occupied outside the home, the mother asked another woman or girl from her household (as observed by CNP workers) to attend NE as this was the 
condition for receiving the FS. In this case, the direct effect on the child's nutritional status of his/her mother's feeding and health practices could not occur as expected.

Child's sex and twin status and mother's ethnicity were also linked to a certain extent to the change in underweight status. Just before the first year and then during the course of the second year of the CNP in Diourbel that are the subject of this work, we conducted population surveys based on an exhaustive sample of the 6-36-month-old children in the neighbourhood targeted by the CNP9. It appeared that being a twin was a risk factor for underweight whereas mother's ethnicity or occupation was not linked to the prevalence of underweight. Moreover, the link between age or sex and the prevalence of underweight in the population concerned was inverse compared with the effect of age or sex on benefit from the CNP. Indeed, prevalence of underweight was lower in the youngest children, and lower in girls (26\%) than in boys $(30 \%)^{9}$. This comparison is consistent with findings reported by Ruel et al., who showed that the 'risk approach', which assumes that individuals at risk will benefit more from nutrition interventions, should be replaced by the use of specific indicators of differential benefit ${ }^{29}$. The lower WA improvement in children whose mother's ethnicity was Serer cannot be explained with present data but could be linked with the fact that at recruitment, the proportion of underweight was $70 \%$ in children whose mother's ethnicity was Serer, whereas it was only $55 \%$ in other ethnicity categories $(P<0.0001)$.

As a limitation of the study, it has to be noted that we did not take into account other determinants which could have affected the growth outcomes of the children such as low birth weight, HIV/AIDS, tuberculosis and parasite infestation. Indeed, morbidity of the children could limit the benefit obtained from FS or the possibility of catch-up growth. However, CNP data were not collected in order to monitor children's morbidity. Moreover, birth weight value was not available for more than $80 \%$ of the children in the targeted neighbourhoods in Diourbel.

\section{Choice of indicators}

Growth assessment is the single measurement that best defines the health and nutritional status of young children, because disturbances in health and nutrition, regardless of their aetiology, invariably affect child growth ${ }^{30}$. Various anthropometric indices can be used to assess child growth status. Height-for-age portrays performance in terms of linear growth, weight-for-height reflects body proportion and is particularly sensitive to acute growth disturbances, and WA represents a synthesis of both linear growth and body proportion ${ }^{31}$. In large-scale interventions or surveys the most commonly used index is WA, although its composite nature makes interpretation complex. However, short-term change, especially reduction in WA, may reasonably be used as a proxy for change in weight-forheight ${ }^{32}$. We could thus assume that the nutrition improvement observed among children who participated in the CNP was mainly due to a reduction in the prevalence of low weight-for-height. Moreover, an absence of recovery could be explained by severely underweight children but, also, by low height-for-age index, a problem that probably cannot be solved in the time scale of an intervention such as the $\mathrm{CNP}^{21}$. In such a case, results on the effectiveness of the CNP or the effect of initial WA value should be interpreted with care. This highlights the importance of the targeting or monitoring criteria when taking into consideration the services provided and the change in anthropometric status expected.

In the present study, change in anthropometric status was assessed from two repeated measurements on the same children. Thus a regression to the mean phenomenon ${ }^{33}$ cannot be completely ruled out, especially when a low initial WA value reflects a high probability of growth improvement. However, models were adjusted for initial WA value to take account of this phenomenon to a certain extent.

Benefit from CNP was examined at the level of children participating in the project. However, an improvement in anthropometric status is also expected at the level of the overall population ${ }^{1,2}$, and this is the subject of another study to evaluate the impact of the CNP.

\section{Conclusion}

After adjustment for services received and initial WA status of children, we identified determinants of differential benefit from the Senegal CNP and they differed from the factors usually linked with underweight in the overall population. Although the present study used data that were not collected specifically to provide explanations of the observed effects, we are in a position to recommend further steps to improve the intermediate outcomes of such nutritional interventions. Six months of CNP services may not be sufficient for catch-up growth of severely underweight children, and, to derive maximum benefit from CNP, these children may have to be enrolled for a longer period of time. Beyond the anthropometric index value, it would be worthwhile to pay special attention to girls, younger children and twins, when the mother works outside the home or, depending on the context, belongs to a specific ethnic group. Moreover, it should be underlined that even though they showed some improvement, onethird of the underweight children participating in the project did not show the expected nutritional recovery; one explanation could be stunting, the most prevalent growth failure in developing countries. Use of the WA index cannot specifically identify stunted children.

\section{Acknowledgements}

This study was supported by the Institute of Research for Development (IRD), France. The authors are indebted to the CNP staff in AGETIP in Dakar and Diourbel for facilitating access to CNP centres in Diourbel. We express 
our sincere thanks to them for allowing us to use the CNP individual beneficiaries' forms and to computerise their data. The authors would also like to thank all CNP workers in Diourbel for their cordial welcome, as well as for facilitating access to their archives, and for their kind help when we collected information from their documents.

\section{References}

1 World Bank. Staff Appraisal Report, Republic of Senegal, Community Nutrition Project. Report No 14004-SE. Washington, DC: Population and Human Resources Division, Western Africa Department, Africa Region, 1995.

2 République du Sénégal/Agence d'Exécution des Travaux d'Intérêt Public (AGETIP)/Projet de Nutrition Communautaire. Présentation du Projet de Nutrition Communautaire. Dakar, Sénégal: AGETIP, 1997.

3 Marek T, Diallo I, Rakotosalama J. Successful contracting of prevention services: fighting malnutrition in Senegal and Madagascar. Health Policy and Planning 1999; 14: 382-9.

4 Ndiaye S, Diouf PD, Ayad M. Enquête démographique et de santé au Sénégal (EDS-II) 1992/93. Demographic and Health Surveys. Calverton, MD: Macro International Inc., 1994.

5 United Nations Children's Fund (UNICEF). Evaluation des objectifs intermédiaires (MICS). Dakar, Senegal: UNICEF, 1996.

6 World Health Organization. WHO Global Database on Child Growth and Malnutrition [online]. Available at http://www. who.int/nutgrowthdb/en/. Accessed 4 May 2005.

7 République de Sénégal. Recensement Général de la Population et de L'Habitat de 1988. Dakar, Sénégal. Ministère de L'Economie, des Finances du plan, Direction de la prévision et de la Statistique, 1992.

8 Gartner A, Maire B, Kameli T, Traissac P, Delpeuch F. Process evaluation of the Senegal Community Nutrition Project: an adequacy assessment of a large scale urban project. Tropical Medicine and International Health 2006; 11: 955-66.

9 IRD Nutrition Unit. [Results of the Survey for the CNP Impact Evaluation in Diourbel. Final Report of the NUT 88 Contract]. Dakar, Sénégal: Agence d'Exécution des Travaux d'Intérêt Public/Projet de Nutrition Communautaire, 1998.

10 World Health Organization (WHO). Measuring Change in Nutritional Status: Guidelines for Assessing the Nutritional Impact of Supplementary Feeding Programs. Geneva: WHO, 1983.

11 Dean AG, Dean JA, Coulombier D, Brendel KA, Smith DC, Burton AH, et al. Epi-Info Version 6, A Word Processing, Database and Statistics Program for Public Health on IBMcompatible Micro-computers. Atlanta, GA: Centers for Disease Control and Prevention, 1994.

12 Searle SR. Linear Models for Unbalanced Data. New York: John Wiley, 1987.

13 Hosmer DW, Lemeshow S. Applied Logistic Regression. New York: John Wiley, 1989.

14 Traissac P, Martin-Prevel Y, Delpeuch F, Maire B. [Logistic regression vs other generalized linear models to estimate prevalence rate ratios]. Revue d'Épidémiologie et de Santé Publique 1999; 47: 593-604.

15 Zou G. A modified Poisson regression approach to prospective studies with binary data. American Journal of Epidemiology 2004; 159: 702-6.

16 Rothman KJ, Greenland S. Modern Epidemiology, 2nd ed. Philadelphia, PA: Lippincot Williams \& Wilkins, 1998.
17 Allen LH, Gillespie SR. What Works? A Review of the Efficacy and Effectiveness of Nutrition Interventions. Nutrition Policy Paper No. 19. Geneva/Manila: United Nations Administrative Committee on Coordination, Sub-Committee on Nutrition in collaboration with the Asian Development Bank, 2001; 123 pp.

18 Bijlsma M, McClean D. Assessment of a take home child supplementary feeding programme in a high density suburb of Mutare City, Zimbabwe. Central African Journal of Medicine 1997; 43: 16-20.

19 Caulfield LE, Huffman SL, Piwoz EG. Interventions to improve intake of complementary foods by infants 6 to 12 months of age in developing countries: impact on growth and on the prevalence of malnutrition and potential contribution to child survival. Food and Nutrition Bulletin 1999; 20: 183-200.

20 Levinson FJ, Lorge Rogers B, Hicks KM, Schaetzel T, Troy L, Young C. Monitoring and evaluation of nutrition programs in developing countries. Nutrition Reviews 1999; 57: 157-64.

21 Walsh CM, Dannhauser A, Joubert G. The impact of a nutrition education programme on the anthropometric nutritional status of low-income children in South Africa. Public Health Nutrition 2002; 5: 3-9.

22 Tollman SM. The Pholela Health Center - the origins of community-oriented primary health care (COPC). South African Medical Journal 1994; 84: 157-63.

23 Lartey A, Manu A, Brown KH, Peerson JM, Dewey KG. Predictors of growth from one to 18 months among breastfed Ghanaian infants. European Journal of Clinical Nutrition 2000; 54: 41-9.

24 Guldan GS, Fan HG, Ma X, Ni ZZ, Xiang X, Tang MZ. Culturally appropriate nutrition education improves infant feeding and growth in rural Sichuan, China. Journal of Nutrition 2000; 130: 1204-11.

25 Santos I, Victora CG, Martines J, Gonçalves H, Gigante DP, Valle NJ, et al. Nutrition counselling increases weight gain among Brazilian children. Journal of Nutrition 2001; 131: 2866-73

26 Penny ME, Creed-Kanashiro HM, Robert RC, Narro MR, Caulfield LE, Black RE. Effectiveness of an educational intervention delivered through the health services to improve nutrition in young children: a cluster-randomised controlled trials. Lancet 2005; 365: 1863-72.

27 Hossain SMM, Duffield A, Taylor A. An evaluation of the impact of a US\$ 60 million nutrition programme in Bangladesh. Health Policy and Planning 2005; 20: 35-40.

28 Treche S. Etude sur l'utilisation de la farine du Projet de Nutrition Communautaire dans les foyers. Dakar, Sénégal: Diagram Consulting, 1998.

29 Ruel MT, Habicht JP, Rasmussen KM, Martorell R. Screening for nutrition interventions: the risk of the differential-benefit approach. American Journal of Clinical Nutrition 1996; 63 : $671-7$.

30 de Onis M, Monteiro C, Akre J, Clugston G. The worldwide magnitude of protein-energy malnutrition: an overview from the WHO Global Database on Child Growth. Bulletin of the World Health Organization 1993; 71: 703-12.

31 WHO Working Group. Use and interpretation of anthropometric indicators of nutritional status. Bulletin of the World Health Organization 1986; 64: 924-41.

32 World Health Organization (WHO). Physical Status: The Use and Interpretation of Anthropometry. WHO Technical Report Series No. 854. Geneva: WHO, 1995.

33 Barnett AG, van der Pols JC, Dobson AJ. Regression to the mean: what it is and how to deal with it. International Journal of Epidemiology 2005; 34: 215-20. 